\title{
Beatriz Sarlo en Punto de Vista*
}

Beatriz Sarlo in Punto de Vista

José Luis De Diego a

Universidad Nacional de La Plata, Argentina

lamy@speedy.com.ar

ORCID: https://orcid.org/0000-0003-4180-2205
DOI: https://doi.org/10.11144/Javeriana.cl24-47.bspv

Recibido: 08 Febrero 2017

Aceptado: 17 Mayo 2017

Publicado: 30 Diciembre 2020

\section{Resumen:}

Este trabajo ha seleccionado como corpus de análisis los más de ochenta artículos, reseñas e intervenciones en debates de Beatriz Sarlo en Punto de Vista. Con el fin de ordenar ese corpus, lo hemos dividido en cuatro apartados: 1) literatura argentina: el pasado; 2) literatura argentina: el presente; 3) intelectuales; 4) teoría literaria, teoría cultural. En dichos apartados, se reseñan artículos y se procura postular, para cada caso, algunas hipótesis interpretativas.

Palabras clave: Beatriz Sarlo, Punto de Vista, literatura argentina, intelectuales, teoría literaria, teoría cultural.

Abstract:

This paper has selected Beatriz Sarlo's more than eighty articles, reviews and debate interventions published in Punto de Vista magazine as a text corpus for analysis. In order to organize said corpus, we have divided it into four sections: 1) Argentinian literature: The past; 2) Argentinian literature: The present; 3) intellectuals; 4) literary theory, cultural theory. All the sections comprise reviews of the articles and seek to propose, for each case, a set of interpretative hypotheses.

Keywords: Beatriz Sarlo, Punto de Vista, Argentinian literature, intellectuals, literary theory, cultural theory.

No resulta sencillo recortar el objeto que el título de este artículo sugiere. $Y$ esto por dos razones. La primera es que desde sus orígenes Punto de Vista tuvo una impronta fuertemente colectiva. Las intervenciones más significativas de la revista en el debate cultural, político y literario constituyeron decisiones y proyectos de carácter grupal y programático. Así, es difícil pensar en la labor de Beatriz Sarlo en la reinterpretación de Sur o en la valoración de la obra de Juan José Saer sin tener en cuenta los aportes de María Teresa Gramuglio; o en su polémica duradera contra las diferentes formas de populismo ideológico y cultural, si no es articulada con los trabajos de Carlos Altamirano. Si es frecuente denominar a Sur como la revista de Victoria Ocampo, o a Contorno como la revista de los Viñas, es raro, muy raro, referirse a Punto de Vista como la revista de Sarlo; quizás porque el carácter colectivo de la empresa resultó exitoso y los lectores y críticos se han acostumbrado a escuchar la voz de una formación intelectual que tenía algo de coral. Cuando en el número 79, de agosto de 2004, se publicaron las renuncias de Carlos Altamirano, María Teresa Gramuglio e Hilda Sabato — tres miembros históricos del consejo de dirección, dos de ellos fundacionales-, más allá de los conflictos internos que motivaron las renuncias, lo que parecía quedar en claro es que la revista quedaba malherida, porque iba a ser muy difícil recomponer esa voz colectiva.

La segunda razón es que la producción de Sarlo en la revista está fuertemente imbricada con sus libros. Buena parte de sus artículos fueron recopilados en volúmenes, como el temprano Ensayos argentinos (1983), en colaboración con Altamirano, o el más reciente Escritos sobre literatura argentina (2007), editado por Sylvia Saítta. Otros no fueron publicados como artículos, pero se transformaron en el embrión de capítulos o partes de libros, tal es el caso de los trabajos publicados en los números 47 (“; Arcaicos o marginales? Situación de los intelectuales en el fin de siglo") y 48 ("El relativismo absoluto o cómo el mercado y la sociología

Notas de autor

a Autor de correspondencia. Correo electrónico: lamy@speedy.com.ar 
reflexionan sobre estética") de Punto de Vista, que formarán parte de las secciones "Intelectuales" y "El lugar del arte", respectivamente, de Escenas de la vida posmoderna (1994).

Entonces, si la labor crítica y ensayística de Sarlo forma parte de una voz colectiva y si se la puede rastrear, acaso más elaborada y sistemática, en sus libros, ¿por qué detenerse en ese objeto artificialmente aislado, heterogéneo y prolífico, extendido a lo largo de treinta años? La razón, o al menos una pauta de lectura e interpretación, puede encontrarse en la nota "Final" publicada, a manera de recapitulación y despedida, en el número 90:

[La revista me dio] en segundo lugar, una escritura: no un lugar donde escribir, sino una manera de escribir sobre literatura y política. Si tiene algún valor lo que he escrito, lo mejor lo he escrito en Punto de Vista; no hay nada que me guste más que ese impulso que, después de leída una novela o en medio de una coyuntura política, me conduce de modo irrefrenable a escribir para la revista. Ella (no sus lectores) me pedía lo que yo terminaba escribiendo. (2)

Se trata, entonces, de advertir las marcas de esa escritura y cómo el impulso "irrefrenable" se transformaba, en la medida que un artículo lo razonaba y le proveía una escritura, en un sistema de pensamiento, intervención polémica y agenda de los debates del campo intelectual y literario.

Indicamos brevemente algo ya sabido: la revista apareció en marzo de 1978 y comenzó a publicarse bimestralmente; luego, el espacio entre número y número se amplió y se publicaron tres números por año. Se editó regularmente hasta el número 90, de abril de 2008 (en la portada se enuncia "30 años, 90 números, fin"). De esta manera, nuestro corpus "Beatriz Sarlo en Punto de Vista" es aproximadamente mensurable, aunque los formatos se solapen y confundan: 78 artículos y reseñas (tres de ellos, los primeros, firmados como Silvia Niccolini), 3 artículos en colaboración (dos con Carlos Altamirano y uno con Hilda Sabato), y 8 intervenciones en debates o mesas de discusión; de los 90 números de la revista, solo en nueve no se publican colaboraciones con su firma (números 5, 9, 12, 14, 23, 29, 31, 67 y 68). Las publicaciones de Sarlo en la revista son las más numerosas del equipo de conducción, pero, además, son las más heterogéneas. Gramuglio enfoca sus trabajos, por lo general, en temas literarios; Altamirano se especializa en la historia de las ideas; Vezzetti, en el psicoanálisis y la memoria colectiva; Gorelik, en el urbanismo, y así el resto. Sarlo parece ser la única que expande su actividad hacia una amplitud disciplinaria que excede cualquier límite que le impongan las especializaciones, de manera que un modo de organizar el corpus referido es intentar ordenar esos campos temáticos sobre los que interviene la actividad crítica de la ensayista. Por momentos, sobre todo en los primeros años de la revista, esa actividad parece tener un carácter más programático (por ejemplo, recuperar y reinterpretar ciertas tradiciones críticas argentinas); en otros momentos, parece responder, algo más azarosamente, al impulso "irrefrenable" (por ejemplo, en sus dos artículos sobre la obra de Sebald). Procuremos, pues, esa organización. ${ }^{1}$

\section{Literatura argentina. El pasado}

En el número 1 de Punto de Vista, Sarlo publica, con seudónimo, una reseña sobre un libro de Natalio Botana. ${ }^{2}$ Leído hoy, parece un texto poco significativo; sin embargo, tiene un sentido oblicuo. Ha dicho la autora: "Se tomaba por ejemplo, para hacer una nota bibliográfica, un libro como El orden conservador, de Natalio Botana, y a propósito de esa nota se hablaba de la república y de la democracia. ${ }^{3}$ Según se ha dicho en repetidas ocasiones, en los años más sombríos de la dictadura, aquellos primeros textos tenían algo de mensaje cifrado e iban en busca de un lector que pudiera encontrar las claves de su desciframiento. ${ }^{4} \mathrm{El}$ modo indirecto más frecuente para hablar del presente censurado fue hablar del pasado: los artículos de la revista que visitan críticamente el siglo XIX argentino fueron, casi todos, publicados en esos primeros números. Sobre Sarmiento, por ejemplo, escriben Nicolás Rosa en el número 2, Ricardo Piglia en el 8 y Sarlo y Altamirano en el 10, y luego ese interés se diluye. ${ }^{5}$ El lugar que ocupa la literatura argentina en Punto de Vista parece 
habilitar una comprobación bastante sencilla: a medida que la dictadura se debilita y se acerca la recuperación democrática, el objeto de los críticos de la revista va desplazándose del siglo XIX al XX.

En el número 4 (noviembre de 1978), Sarlo y Altamirano publican el primero de los artículos en colaboración; ${ }^{6}$ la reivindicación de Martínez Estrada, en el contexto de ese número, resulta programática, ya que el contenido del artículo es resaltado en la tapa, junto con un reconocimiento a la importancia de Contorno en la cultura argentina. De manera que la revista enlaza y articula, por un lado, el homenaje a la publicación que se rescata como un valioso antecedente, y, por otro, al autor que aquella revista reconocía, con sus claroscuros y contradicciones, como referente y guía; esto es, se retoma y prolonga una operación crítica propia de Contorno. El trabajo reconoce el valor de un libro capital de Martínez Estrada, Muerte y transfiguración de Martín Fierro, a los treinta años de su publicación, pero lo reconoce de un modo opinante y contencioso: mientras destaca la originalidad crítica de sus argumentos en la lectura del poema de Hernández ("Uno de los pocos libros importantes que ha producido la crítica literaria en Argentina" "Martínez Estrada" 3]), atenúa y discute la validez de sus asertos en tanto ensayo del "ser nacional”. El libro de Martínez Estrada se suma a la tradición de trazar diagnósticos sobre el país a través del Martín Fierro, y en ese momento exhibe sus fallas (irracionalismo, esencialismo, "prefreudiano") y sus excesos, acentuados en el contexto nacional de 1948. Hay allí, en germen, al menos tres movimientos que continuarán en el futuro: revisar, con el Martín Fierro, la tradición literaria argentina; debatir con las diversas formas del nacionalismo cultural; reivindicar una línea de actividad crítica que asume (como luego dirá de Viñas) que toda estética implica una moral. El primero de estos movimientos se retoma aprovechando otras efemérides, en este caso, los cien años de la Vuelta, que motivó los tres textos sobre el Martín Fierro publicados en el número 7 (noviembre de 1979), a cargo de Gramuglio, Sarlo y Altamirano. ${ }^{7}$ Pero más significativo, por su extensión y densidad critica, es el trabajo sobre Sarmiento, el segundo en colaboración con Altamirano, publicado en el número 10 (noviembre de 1980). Se trata de ver, a la manera de Auerbach, en escenas emblemáticas que condensan sentidos, el modo de funcionamiento de la sociedad en el texto. Así, el episodio de "el minero que lee" deriva en una hipótesis sobre la construcción de una identidad a partir de un doble linaje: uno, el que se construye desde el esfuerzo de quien sale de la pobreza y triunfa, y pone de manifiesto la importancia de una estirpe, el valor de una genealogía, la "gente decente"; dos, la expansión de la familia pobre hacia las élites rectoras, según el modelo de los founding fathers que admiró en los Estados Unidos. A la manera de los héroes de la novela realista (Rastignac, Sorel), Sarmiento construye un linaje para su propio héroe: "a mi progenie me sucedo yo" ("Identidad" 19). Se podría afirmar que en los trabajos hasta aquí reseñados se agota el siglo XIX como objeto de la labor crítica de Sarlo en Punto de Vista; a partir del número siguiente, el pasado se acerca al presente, los clásicos visitados ahora serán del siglo XX.

Sin duda, uno de los momentos más significativos de la tarea crítica de Sarlo lo constituyen sus trabajos sobre la obra de Borges. En Punto de Vista se publicaron cuatro ${ }^{8}$ que tienen, podríamos decir, una estructura de fuga: sin caer en la autocita, en los artículos algo se retoma y algo se expande del anterior, como si las hipótesis se fueran perfeccionando en distintos momentos y con enfoques ligeramente diferentes. En los dos primeros, se analizan las operaciones intelectuales borgeanas en tanto Borges es integrante de una formación. Por un lado, desde la revista Martín Fierro, los jóvenes vanguardistas adoptan a Macedonio Fernández como figura rectora y eso les permite abrir un frente polémico con Boedo y la narrativa social; pero, además, se diferencian de Boedo, Quiroga y Gálvez, a partir de la caracterización y recorte de los públicos lectores y del mercado. Es en el marco de esas estrategias que Borges produce el original cruce entre criollismo y vanguardia: Sarlo potencia la audacia de la apuesta borgeana a partir de una novedosa caracterización — “criollismo urbano de vanguardia" - que se transformará en un punto de partida obligado en la proliferante crítica sobre el autor de Ficciones. Por otro lado, desde los primeros números de la revista Sur, Borges consolida ese cruce mediante artículos que resultan excéntricos respecto de los contenidos de la publicación. Sarlo postula una relación que sorprende entre Borges y Víktor Shklovski, uno de los iniciadores y referentes del formalismo ruso, por la importancia que ambos le asignan a los cómo por encima de los por qué, y por el interés que ambos prestan 
a los géneros "menores", como el relato oral y el policial. En el tercer artículo de la serie, publicado siete años después, Sarlo produce otro cruce, que en algún sentido proviene del anterior: transforma "las orillas" como tema recurrente en Borges en un lugar de enunciación de su literatura, una metáfora y cifra de su proyecto. A través de una lectura de Evaristo Carriego, Sarlo nos dice que Borges se sitúa contenciosamente en relación con el centro del sistema literario argentino representado por Lugones y, más oblicuamente, por Don Segundo Sombra de Güiraldes, al que Borges desnacionaliza con referencias a Kipling y a Mark Twain. Las "orillas", entonces, son ahora el lugar del mundo desde el cual Borges se propone ser un escritor universal; a partir de esta operación, "la literatura argentina se reorganiza por completo, desde la tradición gauchesca la ficcionalización de la teoría del intertexto". En el cuarto artículo, la autora advierte que, aunque Borges se resistió siempre a un uso político de la literatura, en sus relatos existe una recurrencia: una pregunta sobre el orden. Así, buena parte de sus cuentos, como "Deutsches Requiem", "La biblioteca de Babel", "La lotería en Babilonia" o "El informe de Brodie", pueden leerse como respuestas, desde la reelaboración del género fantástico, ante un mundo inquietante y perturbador.

Otro de los núcleos de interés en las intervenciones de Sarlo en Punto de Vista es el trabajo sobre formaciones intelectuales identificadas con publicaciones periódicas, en especial Sur y Contorno. En el número 17 (abril-julio de 1983), la revista dedica un dossier a Sur, en el que escriben Gramuglio, Sarlo y Jorge Warley. ${ }^{10}$ El objetivo declarado es combatir el estereotipo asentado en la crítica de izquierda que asocia a Sur con la oligarquía, como si el proyecto encabezado por Victoria Ocampo fuera la representación emblemática de una ideología de clase. En el trabajo de Sarlo, focalizado en el americanismo, se advierte en la revista la coexistencia de al menos dos formas opuestas de considerar el problema: un americanismo optimista, marcado por cierto juvenilismo y una proyección de futuro (encarnado en Waldo Frank y en la propia Ocampo), y un americanismo pesimista, que se interroga de modo obsesivo por los males congénitos del continente. Respecto de Contorno, habría que mencionar, en primer lugar, el explícito reconocimiento, ya mencionado, incluido en el número 4 de Punto de Vista; ${ }^{11}$ en un encabezamiento sin firma, se destaca que "la validez del programa de Contorno respecto de la revisión crítica del pensamiento, la literatura y la política nacionales [...] sigue vigente" (7). ${ }^{12}$ En ese sentido, la elección de la revista de los años cincuenta como el antecedente con el que Punto de Vista se enlaza y reconoce, se prolonga en dos trabajos de Sarlo. El primero de ellos se publicó en el número 13 de noviembre de 1981; su título retoma la metáfora de los "dos ojos" que Viñas utilizó para leer a Mármol y el romanticismo argentino. ${ }^{13}$ Según la autora, Contorno define un ellos y un nosotros; mientras que el ellos es variable (pueden ser Mallea, Murena, Sur y la oligarquía, los escritores comunistas), el nosotros es negatividad (de ahí el ya clásico bautismo de "parricidas"). Los "dos ojos" se reproducen en Contorno: Echeverría-Rosas, Borges-Arlt, peronismo-antiperonismo; y, sobre estas tensiones, la revista traza un diagnóstico político, fundado en una ética — un compromiso- de la labor crítica. Dos números después, Sarlo decide un gesto doblemente anómalo: publicar una reseña de un libro de crítica literaria de un autor argentino -David Viñas - (es la única escrita por la autora en Punto de Vista) y hacerlo sobre un libro anacrónico - Literatura argentina y realidad politica - (publicado 18 años antes). ${ }^{14}$ La anomalía de esa decisión se justifica, una vez más, en haber encontrado en el libro de Viñas un modelo de crítica: leer el texto literario dentro del texto social. Aquel libro, que representó una irrupción polémica y saludable en los "años dorados del formalismo", arriesgaba una lectura nueva, inteligente y arbitraria de la tradición literaria nacional, de la mano del compromiso sartreano, de las lecturas de Lucien Goldmann y del Barthes de El grado cero de la escritura.

No pretendo agotar (no podría hacerlo, por límites de espacio) todos los trabajos publicados por Sarlo en la revista; solo intento enfocarme en los núcleos que se prolongan en más de un trabajo y que se transforman en programa crítico o en un proyecto de investigación sostenido en el tiempo. Apenas dejo una mención de dos artículos correspondientes a este apartado. Uno: el único dedicado a la narrativa de Roberto Arlt, ${ }^{15}$ lo que contrasta visiblemente con el interés demostrado por el autor de El juguete rabioso en libros y demás 
publicaciones; ${ }^{16}$ es como si ese interés fuera más personal (de Sarlo), pero no encajara demasiado con el proyecto colectivo encarnado en la revista. Dos: el único artículo de la autora dedicado a una obra poética; en este caso, con motivo de la edición de la Obra Completa del poeta santafesino Juan L. Ortiz. ${ }^{17}$

\section{Literatura argentina. El presente}

La crítica aplicada a textos literarios argentinos recientemente publicados adopta, por lo general, la forma de la reseña, aunque a veces se parte de planteos más abarcadores y se desemboca en la reseña como pieza de un argumento mayor; así ocurre, por ejemplo, en los artículos que incluyen las reseñas de El oído absoluto, de Marcelo Cohen, y de El pasado, de Alan Pauls. ${ }^{18}$ Dado que la sección "Libros" se publicó hasta el número 32 (abril-junio de 1988), las reseñas abundan en ese primer período de la revista y luego van menguando o se incorporan, como queda dicho, a formatos más cercanos al artículo. En primer lugar, es necesario hacer un breve repaso de los autores que Sarlo reseña, según su orden de aparición: ${ }^{19}$ Juan José Saer $(10,46,59)$; Enrique Medina (13); Guillermo Saccomano y María Esther de Miguel (20); Antonio Dal Masetto (21); Rodolfo Rabanal (22); Andrés Rivera (27); Mario Szichman (29); Marcelo Cohen (37); Rodolfo Fogwill (49, 71); Roberto Raschella (51, 62); Luis Gusmán (54); Sergio Chejfec (57); Martín Caparrós y Matilde Sánchez (64); Alan Pauls (78); Alejandro López (83); y Luis Chitarroni, Aníbal Jarkowski y Leandro Ávalos Blacha (90). No es mi intención aquí reseñar las reseñas, solo pretendo analizar las características y alcances de una labor crítica. En este sentido, los trabajos sobre novelas del presente - en la gran mayoría de los casos se trata de novelas- difieren de los artículos sobre la literatura argentina del pasado. La distancia temporal, si se analiza, por ejemplo, la obra de Borges o la significación de Sur o Contorno, permite una perspectiva más cercana por momentos a la historia de las ideas o incluso a la sociología de corte bourdiano (las tomas de posición de Borges respecto de Lugones o Güiraldes, el ellos y el nosotros de Contorno). En cambio, cuando se trata de reseñas, la autora parece ceñirse mucho más a los precisos límites del texto, en especial al análisis de su escritura y a las estrategias de representación. El hilo conductor que suele guiar las reseñas lo constituye el desarrollo analítico del argumento, y la detención en los núcleos de condensación de sentido, de manera que la extensión no es un dato menor para juzgar el interés de la reseñista en el texto (nótense, por ejemplo, las brevísimas reseñas sobre Saccomano y de Miguel en contraste con la minuciosa y detenida que le dedica a Las nubes, de Saer). ${ }^{20}$

Respecto del censo de escritores y de obras, y más allá de los juicios que puedan hacerse de ese conjunto, sobresale visiblemente el interés sobre la obra de Juan José Saer. Sarlo vuelve en cinco ocasiones sobre la obra de Saer, ${ }^{21}$ y lo hace, podríamos decir, en contrapunto con María Teresa Gramuglio, ${ }^{22}$ lo que constituye una verdadera toma de posición del colectivo Punto de Vista ante quien consideraban el escritor argentino (y el proyecto creador) más valioso, más significativo y más radicalmente original de la segunda mitad del siglo XX. El carácter colectivo del interés sobre el escritor santafesino lo pone de manifiesto "Punto de Vista señala", una columna breve sin firma personalizada que apareció en el número 3 (julio de 1978); aparenta ser una reseña sobre La mayor (publicada dos años antes en Barcelona), pero, en verdad, se trata de un panegírico de Saer y de una protesta, o una manifiesta incomodidad, por el silencio de la crítica ante su obra ("El elogio implícito de una crítica unánime en su silencio" ["Punto de Vista señala” 19]). Las tres reseñas de Sarlo sobre las novelas de Saer pueden leerse como un crescendo en el que los primeros tanteos se transforman en una mayor densidad crítica que deriva en celebración. En un primer momento (Nadie nada nunca), la sorpresa ante la resistencia de un texto esquivo: tiempo presente, expansiones, repeticiones, imposibilidad del movimiento y del placer, mirada y revelación. La segunda (Lo imborrable), trece años después, se escribe sobre la certeza de estar ante un autor plenamente consciente de los problemas narrativos de la novela, a los que resuelve por caminos diferentes a las vanguardias y a los modos habituales con los que la literatura procesa la experiencia. En la tercera (Las nubes), la novela es leída contra un fondo clásico de formatos genéricos 
(novela de aventuras, novela de viajes, novela filosófica), y como un compendio de múltiples referencias (de Aristófanes a Cicerón, de Sarmiento a Mansilla y la gauchesca): Saer ya forma parte de un Parnaso en el que dialoga con la mejor literatura de Occidente. Sin embargo, en el punto alto de la celebración, se multiplican las preguntas: “¿Cómo alcanza el efecto doble de levedad y profundidad? ¿Cómo hace para ser, al mismo tiempo, cómico y serio, amable y pesimista, divertido y difícil?" ("Aventuras” 35). Como si fuera un clásico que no es clásico, que no se adecua al bronce de los indiscutidos, sino que, como la mejor literatura, continúa resistiendo a los asedios críticos y sigue multiplicando las incertidumbres. Esa perplejidad duradera se pone de manifiesto en los dos textos restantes que Sarlo le dedica: el primero, de 2005, es una columna algo más breve, de homenaje y admiración, ante la noticia de la muerte del autor; ${ }^{23}$ el segundo, publicado dos años después, narra la experiencia de lectura de los textos de Saer a lo largo del tiempo, una especie de "historia personal" de sus lecturas. ${ }^{24}$ Caracteriza su obra como trágica: Saer lleva a un puñado de personajes unidos por lazos morales y literarios a la decadencia y a la muerte. Se trata de un materialismo de dimensión metafísica que avanza "describiendo las cosas como si fueran pedazos de una verdad de la experiencia que nunca podría comprobarse" ("El mejor" 1). La percepción — focalizada en la "zona" de su experiencia- tiene una doble cara: es lo único que poseemos, pero nunca nos brinda certezas, sino que multiplica la incertidumbre ante lo percibido. El título de su columna de 2005, “El mejor”, cierra el ciclo de su canonización; aunque se trate de un escritor de minorías, Sarlo percibe en esa obra la consistencia y la perdurabilidad del gran arte.

Pero la grandeza de Saer se acrecienta en las elecciones estéticas de Sarlo, por contraste, por el peso de algunos silencios significativos. Es casi un lugar común de la crítica, y de los volátiles consensos académicos, que en los años ochenta asistimos a la progresiva canonización de Manuel Puig, Juan José Saer y Ricardo Piglia. ${ }^{25}$ Muchos otros han querido, con argumentos menos convincentes, que, ya entrados los años noventa, César Aira se sume a ese podio no exento de malentendidos y entredichos. En cualquier caso, no es este el lugar para edificar ni derribar cánones; solo quiero hacer notar que, aparte de Saer, el resto de los autores está ausente como objeto de la crítica de Sarlo en Punto de Vista. ${ }^{26}$ Si tenemos en cuenta que en los Escritos sobre literatura argentina, la compilación ya referida, se incluyen solamente una breve columna escrita en ocasión de la muerte de Manuel Puig y una reseña sobre Prisión perpetua, de Ricardo Piglia, ambas publicadas en el periódico Página/12, podemos conjeturar que el silencio sobre Puig, Piglia y Aira forma parte de una decisión —una opción- estética. ${ }^{27}$ Algunas razones que motivan el silencio pueden rastrearse en los dos "panoramas" sobre la literatura argentina que Sarlo publica en la revista; me refiero a "Literatura y política" y a "Sujetos y tecnologías. La novela después de la historia”: ${ }^{28}$ interesa poner estos dos artículos en secuencia porque el primero puede pensarse como el sustrato argumentativo del segundo y porque median entre uno y otro nada menos que veintitrés años.

En "Literatura y política" se pasa revista a la literatura argentina de los años de exilio, represión y crisis, y allí se multiplican las preguntas pertinentes acerca de ese contexto adverso: “¿Con qué instrumentos se escribe, trabajando sobre qué experiencia?, [...] ¿ para quién se escribe?” (8). Existe una suerte de doble determinación: una externa, la noche negra de la dictadura (el número 19, en el que se publica el artículo, es el primero en democracia), y otra interna, propia del sistema literario. En este punto, Sarlo formula una hipótesis muchas veces citada:

En los años setenta se produce un giro en la narrativa argentina: del sistema de la década del sesenta, presidido por Cortázar y una lectura de Borges (lectura contenidista, si se me permite la expresión), se pasa al sistema dominado por Borges, y un Borges procesado en la teoría literaria que tiene como centro al Intertexto. ("Literatura" 8$)^{29}$

De manera que asistimos a novelistas atravesados por las teorías de la literatura que manifiestan una explícita desconfianza hacia la narración clásica. Si la violencia reciente había disuelto todas las certezas, la literatura daba testimonio de ello poniendo en crisis la narración y la representación: ¿cómo contar?, ¿desde dónde narrar?, ¿ hay una historia? Estamos ante novelas que se imponen hablar de la historia, pero lo hacen de un modo oblicuo y autorreflexivo. El panorama se detiene, en especial, en tres novelas (Respiración artificial, 
de Piglia [1980], Hay cenizas en el viento, de Carlos Dámaso Martínez [1982] y Nadie nada nunca, de Saer [1980]) y cierra con una referencia a las narrativas de David Viñas y Jorge Asís como los extremos moralista y cínico del espectro. En el artículo de 2006, se parte de la certeza expuesta en el anterior: "Hace casi un cuarto de siglo, la novela argentina y la crítica [...] coincidieron en una pregunta: ¿cómo la ficción entiende la historia?" (1). Y, entre esas "figuraciones de la historia", se mencionan obras de Piglia, Saer, Rivera, Moyano, Tizón, Martini y Dal Masetto. Según Sarlo, algunas novelas como Villa, de Luis Gusmán, y Las islas, de Carlos Gamerro, fueron cambiando los modos de referir la historia reciente. Si bien el interrogante sigue vigente y hay autores que vuelven a los años setenta y se repiten la pregunta (Chejfec, Kohan), este ya no representa un eje de la ficción argentina, probablemente porque lo que en los ochenta representaba una novedad, ya no lo es. Otra hipótesis largamente comentada procura caracterizar la narrativa de la primera década del nuevo siglo: "Si la novela de los ochenta fue 'interpretativa', una línea visible de la novela actual es 'etnográfica”" (Sarlo, "Sujetos" 2). Se trata de novelas que tienen al presente como escenario y que utilizan variadas (y aun opuestas) estrategias: el abandono de la trama (lo "disparatado" en Aira, en Daniel Guebel), el registro plano (en la herencia de Puig, Romina Paula, Paula Varsavsky), la salida del registro plano por el exceso (Cucurto: el narrador sumergido, el populismo posmoderno) y las nuevas tecnologías (Daniel Link, Alejandro López). De este modo, los dos panoramas, distantes pero imbricados en sus diagnósticos, han servido para establecer estados del campo que fueron, a su vez, pisos de debate y discusión sobre qué historias representaban nuestros novelistas y cómo lo hacían. ${ }^{30}$

\section{Intelectuales}

Participante de una generación marcada por la figura de Jean-Paul Sartre y los procesos de radicalización política, Sarlo reflexionó activamente —incluso desde sus trabajos en Los Libros (1969-1976) — sobre los intelectuales como grupo social y sobre la función social que es esperable de ellos. En Punto de Vista, de las múltiples referencias dispersas en numerosos artículos es posible recortar tres en las que el tema se aborda en su especificidad y la reflexión se torna más sistemática. ${ }^{31} \mathrm{El}$ primero de ellos, "Intelectuales, ¿̇escisión o mímesis?", fue un ensayo clave porque es uno de los primeros trabajos que traza un cuadro, con "mucho de autobiografía colectiva" (1), de las relaciones entre intelectuales y política en los últimos veinte años en Argentina, y termina con una evaluación de esa relación en el presente; y clave también por las polémicas que suscitó. El intelectual durante la transición enfrenta dos riesgos: el de quedarse petrificado ideológicamente en nombre de la Revolución, e incluso reclamar ese dogmatismo como mérito; y el de pensar que democracia es sinónimo de moderatismo y situarse en ese cómodo lugar. Ante esos riesgos, Sarlo reseña críticamente sus años de formación, en los que la "primacía de la política" terminó "canibalizando" el discurso de los intelectuales y la necesaria autonomía que requiere su práctica; en ese itinerario, reivindica una vez más a los intelectuales de Contorno: de aquella etapa crítica, identificada con la revista de los Viñas, se pasó a una "etapa racionalizadora", en la que se asistió a la rendición de la práctica intelectual, ya que "la acción comenzó a devorar a la razón crítica”. Desde Hayden White, Sarlo caracteriza "las narraciones de la política" de entonces como optimistas, utópicas, redentoristas y mágicas. Finalmente, llega al presente: "Hoy, se han deteriorado las certidumbres" ("Intelectuales, ¿escición o mímesis?" 5); los intelectuales se enfrentan a los riesgos ya delineados en el inicio del artículo, y, para enfrentar esos riesgos de un modo socialmente productivo, es necesario replantearse las relaciones que existen entre cultura, ideología y política, que se encuentran regidas por una tensión necesaria, ya que se trata de instancias no simétricas. "No hay pacto de mimesis entre cultura, ideología y política", concluye Sarlo, "más bien podría decirse que hay diferentes juegos de relaciones entre elementos siempre heterogéneos" ("Intelectuales, ¿escición o mímesis?" 6). Ni mimesis, por lo tanto, ni escisión, la tarea intelectual obliga a "trabajar en y sobre los límites" ("Intelectuales, ¿escición o mímesis?" 6). Sarlo se despega, de este modo, de la actitud nostálgica de la izquierda revolucionaria — de la que ella 
misma formó parte—; se despega, asimismo, del entusiasmo inicial que llevó a una franja de la izquierda progresista a apoyar al alfonsinismo, ya que esta actitud había derivado, en muchos casos, en el "posibilismo", "moderatismo" y conformismo. Pero Sarlo no deja de asumir plenamente los límites y las responsabilidades que implica el trabajo intelectual, y se coloca, mediante una fuerte impronta autobiográfica, en el centro del debate: porque ella volverá una y otra vez sobre esta problemática, y porque otros reconocerán esa centralidad al aceptarla como interlocutora, aun para disentir enfáticamente con sus posiciones.

El segundo artículo, “:Arcaicos o marginales? Situación de los intelectuales en el fin de siglo”, se publica ya entrados los años noventa, durante el menemismo, y el debate que plantea sobre "los intelectuales en el fin de siglo" no se ciñe exclusivamente al caso argentino. Estamos, afirma Sarlo, "en los años finales de un siglo que se pareció muy poco a esta última década" (2). No presenciamos un espíritu de fin de siglo, los últimos años del siglo XX no están representados ni por el decadentismo que caracterizó los estertores del siglo XIX ni por el ansia de un futuro con la Revolución en el horizonte. Alimentado con el lenguaje de los estudios culturales, el fin de siglo se identifica con las políticas de la tolerancia: los nuevos sujetos sociales - minorías étnicas, sexuales, religiosas, culturales- han terminado por ocupar el centro de la esfera pública, exigiendo atención para sus demandas. Esta mutación generó la crisis de los antiguos sujetos históricos, de las ideas de cambio, de las vanguardias y de los valores estéticos de la modernidad; crisis, en fin, de la figura clásica del intelectual. La agenda estatuida por la llamada posmodernidad ha puesto al intelectual universal bajo sospecha y, tras su figura, a toda forma de representación. ${ }^{32}$ Parece haber desaparecido aquella figura de intelectual, representada por el singular magisterio de Sartre, que se hacía cargo de problemáticas generales, aunque no le concernieran personalmente. En el fin de siglo se terminó con la vocación generalizadora que movía a las vanguardias, "cada grupo habla por sí y de sí", y la actividad de los intelectuales solo parece tener eficacia social si devienen en expertos. De manera que se enfrentan a un dilema: o bien se adaptan a lo existente, conformes o derrotados; o bien se suman al mosaico particularista en donde nadie parece pensar en términos de bien común o en proyectos colectivos de transformación social. Incluso, en el ámbito de las minorías académicas, se abrazan a la "especificidad" como un refugio y abandonan las cuestiones de proyección general al dominio del gusto o del interés. La consecuencia de este dilema no resuelto se advierte en la proliferación de lo que Sarlo llama "intelectuales neopopulistas", que no se identifican ni con el pueblo ni con la nación sino con los efímeros éxitos del mercado, porque es lo que persigue y desea la gente. El neopopulismo es una ideología construida sobre un supuesto sentido común, individualista, puramente adaptativa, en tanto la resignación del espíritu crítico que proveía el intelectual clásico produce un indiferentismo ético y estético y una cultura celebratoria de lo banal.

Si entre los dos artículos reseñados mediaban ocho años, y por ende las diferencias resultaban significativas, entre el segundo y el tercero media solo un año, y los argumentos, lejos de variar o mutar, se consolidan y profundizan. El tercer artículo, “¿La voz universal que toma partido? Crítica y autonomía”, parte de una constatación biográfica: nunca, declara Sarlo, se sintió tan alejada, tan "salvajemente separada" de la sociedad argentina, como en los años de las Malvinas, entre el énfasis beligerante del gobierno y de los medios, y la enorme dificultad de hacer oír una voz de disenso. Con la muerte de Sartre, el sociólogo Pierre Bourdieu afirmó que ese lugar ya no estaba disponible, la voz universal que toma partido había entrado en el ocaso. Y ese intelectual en extinción se encuentra asfixiado por la presencia, por un lado, de los expertos y técnicos; por otro, de los intelectuales de los medios. Son ahora los periodistas y los comunicadores quienes ocupan con mayor fuerza el espacio público, y su palabra resulta más escuchada, más persuasiva, más familiar, "la ilusión de una comunidad estrecha": lo radicalmente nuevo de las últimas décadas es la reconfiguración massmediática de la cultura. Respecto del caso argentino, Sarlo afirma que hacia 1974 se terminó de escribir el último capítulo de la novela intelectual, al menos de una variante de intelectual, de aquel que consideraba a la acción política como fundadora de los sentidos de toda otra conducta humana, en la que cualquier crítica que se elevara contra los catecismos en boga pasaba a ser considerada como una debilidad pequeñoburguesa o moralismo, cuando no, directamente, una actitud antirrevolucionaria. El fin de ese modelo, que acaba trágicamente con 
el golpe de 1976, obligó a repensar las relaciones entre pensamiento y acción, entre la actividad intelectual y la praxis política: "Había que pensar todo de nuevo" (8). De allí surgieron los aprendizajes de esos años oscuros, en especial, la convicción de que "el pensamiento crítico es, por definición, autónomo" (8). Y la autonomía del pensamiento crítico fue una posición que debió ser conquistada; por eso, la reflexión sobre la actividad intelectual, más que teórica, se acerca a una especie de epifanía que, en los momentos más duros de la experiencia, rescata la dimensión autobiográfica. Si la primera parte de sus argumentos (la biografía generacional) remite al artículo de 1985, la segunda retoma el de un año atrás: la aparición en escena de un nuevo tipo de intelectual (intelectual "electrónico", lo llama) que procura relacionarse con los nuevos públicos, dejando atrás las antiguas dicotomías entre cultura de élite y cultura popular. El cierre reafirma la existencia de un espacio entre "la hegemonía y la insignificancia" en el que la voz intelectual no tendría que dejar de identificarse con valores que ninguna política progresista debiera resignar.

Como dijimos, en estos artículos resuenan debates sobre la función de los intelectuales que atraviesan el siglo XX, pensados desde el particular contexto argentino que va desde los primeros setenta hasta bien entrada la década menemista. Y ese contexto resulta decisivo para advertir hasta qué punto esa función había cambiado, acaso definitivamente. Norberto Bobbio, en un informe presentado en 1977 ante un congreso del Partido Socialista italiano, planteó lo que llama las "dos condenas" del intelectual bajo la forma de un dilema: "Si toma partido, traiciona, y si no toma partido, deserta" (68). Es decir, el viejo dilema de compromiso y autonomía; en cualquiera de las dos alternativas se arrastra una culpa: la de haber traicionado su independencia o la de haber desertado de su responsabilidad política. Este dilema se puede plantear, algo esquemáticamente, como una relación inversamente proporcional: a mayor autonomía, menor compromiso; a mayor compromiso, menor autonomía. En un artículo publicado en 1992, Pierre Bourdieu refuta este tipo de formulación, mediante una comprobación histórica:

Es solamente a finales del siglo, en el momento en que el campo literario, el campo artístico y el campo científico acceden a la autonomía, que los agentes más autónomos de estos campos autónomos pueden intervenir en el campo político como intelectuales. ("Por una internacional” 189)

No diríamos en este caso que Bourdieu transforma la relación inversamente proporcional en una proporcionalidad directa, sino que convierte a la autonomía en una condición del ejercicio intelectual. Si en un momento se leyó la figura de intelectual comprometido como un pleonasmo, ya que no se concebía (al menos, en teoría) a un intelectual no comprometido; ahora, el intelectual que abandona la autonomía de su actividad deja de serlo, de modo que no hay (al menos, en teoría) un intelectual no autónomo. Ya no, entonces, autonomía versus compromiso, sino autonomía como condición necesaria para el compromiso. ¿Cómo y por qué se produce esta inversión de la teoría de fines de los años setenta a comienzos de los noventa? Planteemos una hipótesis posible: el enemigo es otro y la estrategia, por ende, debe modificarse. Un intelectual podía comprometerse contra el fascismo o la barbarie nazi, contra la omnipresencia represiva del Estado soviético, contra las más variadas dictaduras que se instalaron en nuestro continente, contra el imperialismo norteamericano. La consolidación del proceso conocido como globalización, que implicó en América Latina las nuevas agendas de reforma estructural del Estado, conlleva lo que Bourdieu llama "nuevas amenazas": los intelectuales cada vez más excluidos del debate público; las universidades rendidas ante los intereses de las empresas; la "lógica de la producción comercial" que reemplaza a la producción de vanguardia; la instauración de una nueva tecnocracia de la comunicación; la proliferación de tuttologos (nosotros diríamos opinólogos) como "caballos de Troya" a través de los cuales la heteronomía penetra en el campo de la producción cultural. De Bobbio a Bourdieu, de 1977 a 1992, se pone de manifiesto un fenómeno global que alteró convicciones muy consolidadas sobre los intelectuales y obligó a llevar a cabo replanteos profundos. Beatriz Sarlo fue quizás la intelectual argentina que más visiblemente protagonizó esos replanteos y que con mayor lucidez reflexionó sobre ellos. 


\section{Teoría literaria, teoría cultural}

Se podría decir que el primer trabajo de teoría literaria de Sarlo en Punto de Vista (del que nadie ha hablado) puede pensarse como la antesala de sus trabajos sobre Raymond Williams (de los que se ha hablado mucho). Se trata de una reseña en la que comenta in extenso el libro de Wayne Booth, The Rhetoric of Fiction, publicado originalmente en 1961 y traducido en Barcelona en $1978 .{ }^{33}$ Esta reseña inicial le sirve para uno de los repetidos objetivos teóricos que se advierten en los primeros números de la revista: tomar distancia de la tradición que fundara el formalismo ruso y la crítica anglosajona del new criticism. Las preguntas de Booth, que se interroga sobre la "verdad" de lo literario, derivan hacia las respuestas que ha dado la sociología de la literatura sobre la "credibilidad" del texto como una serie de convenciones culturales. El libro de Booth, que abunda en disquisiciones acerca de la figura del narrador, deja ver las limitaciones del formalismo norteamericano, que coincide en sus límites con el empirismo. En el final de su reseña, Sarlo concluye: "Bien sabemos que, reconocida la utilidad de los instrumentos analíticos propuestos, la cuestión de la crítica nos remite primero a una poética y luego, con todas las articulaciones necesarias, a una teoría de los productos artísticos y culturales" (5). En esta frase hallamos una toma de posición que será coherente y duradera en los trabajos posteriores de la ensayista, en especial en ese incidental “con todas las articulaciones necesarias", el que, con el auxilio de otras herramientas teóricas, derivará en una teoría de las mediaciones.

Cuando se habla del papel fundamental que cumplió Punto de Vista en la importación de teorías que, con el tiempo, resultaron muy influyentes en el campo cultural argentino, suele mencionarse en primer lugar la obra del historiador galés Raymond Williams. Una extensa entrevista y artículos de Carlos Altamirano y de Beatriz Sarlo ponen de manifiesto el particular interés que los conductores de Punto de Vista depositaron en sus teorías. ${ }^{34}$ Como la propia Sarlo lo certifica en un artículo de 1993 ("Raymond Williams: una relectura"), lo que más los atrajo de Williams fue la consideración de un corpus teórico que posibilitara formular una teoría de las mediaciones entre cultura y política; esta permitiría salir de la anulación brutal del espacio público producida durante la dictadura, sin caer nuevamente en la "canibalización" de la cultura por la política que había caracterizado a los primeros setenta; Sarlo la llamó "salida culturalista”. En una entrevista publicada en el número 6 de junio 1979 ("Raymond Williams y Richard Hoggart: sobre cultura y sociedad") se advierte que la mayoría de las preguntas que Sarlo le hace a Williams son de carácter conceptual, como si quisiera centrarse en las categorías teóricas que por entonces tenían un carácter de novedad fuerte: cultura, tradición, hegemonía, estructura de sentimiento, ideología — no hay que olvidar que los libros de Williams más recientes, para 1979, eran libros conceptuales: Keywords (1976) y Marxism and literature (1977)—. En el artículo del número 45 de abril de 1993 ("Raymond Williams: una relectura"), Sarlo recapitula los primeros momentos de la recepción de Williams, en los años del auge del estructuralismo y del marxismo althusseriano, y rescata dos aspectos centrales: "El análisis de los procesos institucionales, tecnológicos y materiales como condiciones de producción de lo simbólico; y el examen de algunas nociones, continuamente redefinidas, que le permitirían considerar la materia histórica de la literatura y la lengua" ("Raymond Williams: una relectura" 12). Además, Williams no solo dotaba a la cultura de cierta autonomía respecto de variadas determinaciones (en especial, la política), sino que también abría puertas para reinterpretar conceptos gramscianos, como el de hegemonía, e incluso podía ponerse en contacto con las teorías del posformalismo ruso. Sarlo lo llama el momento "ecléctico" que posibilitó reponer al sujeto, la historia y la experiencia. Le interesó particularmente la tentativa de reconstruir el "espesor de lo vivido" a partir de la categoría estructura de sentimiento, que venía a ocuparse de un objeto que se consideraba por entonces una verdadera imposibilidad teórica. ${ }^{35}$ La filiación williamsiana de algunos trabajos de Sarlo excede, claro está, sus aportes en Punto de Vista; en 1988 publica Una modernidad periférica: Buenos Aires, 1920 y 1930, un libro tributario de los aportes del culturalismo inglés; y dos años después, junto con Carlos Altamirano, da a conocer un libro de términos, Conceptos de sociología literaria, en el que continúa presente la impronta culturalista. 
Roxana Patiño se ha referido a la importación, operada por la revista, de teorías "no reductivistas" y menciona a Raymond Williams y a Pierre Bourdieu; en efecto, en el número 15 de agosto-octubre de 1982 se publica la (ahora) muy conocida lección inaugural del sociólogo francés en el Collège de France. ${ }^{36}$ Sin embargo, resulta evidente que la recepción de Sarlo, y el interés que demuestra en uno y en otro cuerpo teórico, no es equivalente. Por un lado, no existe ningún trabajo en la revista en el que Sarlo se ocupe específicamente de la tan difundida teoría bourdiana de los campos. Por otro, en un artículo de 1994 se refiere a un efecto claramente nocivo de la perspectiva sociológica aplicada a los debates sobre el arte. ${ }^{37}$ Allí se afirma que era necesario combatir el énfasis sustancialista o esencialista y para ello se recurrió a la "higiene sociológica", pero esta operación resultó un "ácido" que diluyó el problema de los valores y solo nos dejó una definición puramente institucional del arte. La consecuencia fue el "estallido relativista" que brinda una engañosa ilusión de democratismo y en definitiva deja las decisiones respecto del valor artístico en manos del mercado ("El relativismo" 27-31). Como se ve, no hay una actitud celebratoria ante la irrupción exitosa de la sociología de la cultura, sino cierta desconfianza de sus efectos y cierto recelo ante la aplicación mecánica de sus métodos.

Si los aportes teóricos de Raymond Williams resultaron los adecuados para pensar la relación entre cultura y política en los años de la transición; Sarlo recurrió a la obra del filósofo alemán Theodor Adorno para postular un tipo de relación entre ficción y política durante el período dictatorial, ${ }^{38}$ a partir de la diferenciación entre el discurso autoritario y el discurso literario. El régimen discursivo del autoritarismo presupone un fundamento de verdad indiscutible, pero este fundamento solo está basado en razones de fuerza prediscursivas, verdades colocadas más allá de la discusión; organiza los límites de lo permitido y de lo que queda excluido fuera de esa frontera. Ante este monólogo de verdades únicas que pretenden instaurar sentidos fijos para la sociedad, el discurso del arte y de la cultura propone un modelo formalmente opuesto: "El de la pluralidad de sentidos y la perspectiva dialógica" ("El saber del texto" 7). La literatura tuvo y tiene un desafío complejo, que es el de proponer la restauración de la diferencia, poniendo en escena un debate sobre los valores. Cuando la realidad se vuelve opresiva, opaca, sombría, la literatura comienza a construir tramas de sentido - "trabaja sobre un mundo laico"- que plantean lecturas diferentes de ese "núcleo resistente" que constituye lo real; con este fin, articula una pluralidad de regímenes discursivos y de estrategias de ciframiento ("El saber del texto" 7). En los límites de este artículo, Sarlo no desarrolla cuáles son esos regímenes y esas estrategias; lo hará un año después cuando publique el artículo, modificado y ampliado, como parte de un volumen colectivo. ${ }^{39}$ Más persistente, aunque menos sistemática, es la presencia de Walter Benjamin, otro de los grandes pensadores de Fráncfort, en los trabajos de Sarlo en Punto de Vista. Si bien las categorías fundantes de la obra benjaminiana merodean habitualmente en sus ensayos, solo un artículo se refiere explícitamente a Benjamin, pero más que de la filosofía del autor de Iluminaciones, se trata de una invectiva contra buena parte de sus receptores locales. ${ }^{40}$ Se asiste a una suerte de "moda Benjamin", impulsada por la llamativa difusión en la academia argentina de la etiqueta "estudios culturales"; de esta manera, el autor alemán se suma a otras modas, como en su momento lo fueron Foucault o Bajtín. La consecuencia de la divulgación de ciertas teorías como si fueran modas es la banalización y la proliferación de clisés, de lugares comunes que simplifican la complejidad original. Sarlo se detiene en la figura del flâneur y en la ciudad como tema, y advierte que "Benjamin está ensopado en un jarabe puramente léxico" ("Olvidar a Benjamin” 17). La ciudad le interesa al ensayista alemán no porque le interesaban las ciudades, sino porque es un espacio clave para entender el movimiento del arte y el movimiento de las mercancías. Del mismo modo, en sus escritos hay fragmentos, citas y ruinas, pero también hay cierta "nostalgia de totalidad" que parece refutar al Benjamin precursor de la posmodernidad, traducido al "esperanto de los estudios culturales". En este artículo atípico, Sarlo no polemiza con nadie y polemiza con todos, en particular con las modas académicas que se suman acríticamente a las agendas pautadas en instituciones de países centrales, las que devienen con inusitada rapidez en lo que indica y rige la corrección política. 
Cuando se habla de la importación de temas y autores operada por Punto de Vista, suele citarse, en la serie, el artículo de Hans Jauss aparecido en el número 12 de julio-octubre de 1981, traducido por Beatriz Sarlo; se lo presenta como un autor que, ya sea por las modas literarias o por los caprichos editoriales, ha estado silenciado para el público en español. ${ }^{41}$ Sin embargo, las teorías de la lectura difundidas en nuestro país desde inicios de los años ochenta no tuvieron la misma pregnancia ni la misma persistencia en el tiempo que las citadas anteriormente. Cuatro años después, la revista publica un artículo de Terry Eagleton, en el que se refiere irónicamente a las teorías sobre la lectura, y un ensayo de Sarlo en el que, a partir del comentario de Eagleton, tiende una mirada crítica hacia ese "nuevo canon" ${ }^{42}$ Sarlo traza un itinerario, con especial énfasis en los últimos diez años, por las teorías que han tenido como finalidad desacreditar el presupuesto de la unidad del texto; las teorías de la lectura se suman a esa tradición y enfatizan en la experiencia de la lectura (Jauss) y en el placer que provoca (Barthes). El artículo reseña brevemente los aportes de la escuela de Konstanz, de Umberto Eco, Wolfgang Iser, Jonathan Culler y Stanley Fish; en todos esos casos, advierte una suerte de indefinición entre la figura del lector (informado) y el público (empírico), crítica que será central, años después, en los estudios de la lectura como práctica social, desde el punto de vista de la historia cultural (Robert Darnton, Roger Chartier).

Williams y Bourdieu, Adorno y Benjamin, Jauss e Eagleton, el censo de autores y teorías “importados” por la revista, y por Sarlo en particular, podría multiplicarse. Solo he querido mostrar, por un lado, la vigorosa e influyente tarea en el proceso de renovación teórica y crítica que la revista operó desde sus inicios; ${ }^{43}$ por otro, que, puestos en un pie de igualdad, a menudo la sola mención de autores y teorías oculta o solapa las diferencias notorias que se advierten en la recepción de uno y de otro. ${ }^{44}$

\section{Cierre}

Algunas líneas más arriba, mencioné un trabajo de Sarlo sobre la revista Contorno: si Viñas nos había hablado de "los dos ojos" del romanticismo, Sarlo aprovechó la figura para referirse a "los dos ojos" de Contorno. Me siento tentado, pues, a hablar de "los dos ojos" de Punto de Vista, o, más precisamente y para evitar generalizaciones, "los dos ojos" de Sarlo en Punto de Vista. En su artículo de cierre, publicado en el número 90, Sarlo nos dice que la revista "siguió creyendo que la política y la estética debían convivir en sus páginas no porque sus relaciones fueran sencillas, sino, precisamente, por lo contrario: porque son conflictivas, y Punto de Vista siempre vivió del conflicto" (2). La relación estética y política es conflictiva tanto en el campo de la elaboración teórica como en el de la praxis social que se manifiesta en situaciones concretas. Pero ¿por qué conflictiva en el interior de la revista? Porque parece bastante evidente que convivían dos ideologías opuestas y una biblioteca respaldaba sus posiciones políticas y otra, muy diferente, sus opciones estéticas. No es imposible ser reformista en política y vanguardista en arte, pero es una relación que no se aviene pacíficamente; Sarlo no solo era consciente de esa tensión, sino que fue una brillante teórica, precisamente, sobre esa tensión. En su artículo del número 50 (que ya comentamos) cita el libro de Michael Waltzer sobre los intelectuales; allí, Waltzer se pregunta cuál es la distancia que el discurso crítico debe establecer con la sociedad a la que se dirige. Y Sarlo añade: "Esta cuestión, que es completamente irrelevante para el arte, es, en cambio, central para los intelectuales” (“¿La voz...?” 7). Aquí está condensado el conflicto: si se lo mira desde la política —los intelectuales - es central; si se lo mira desde la estética —el arte- es completamente irrelevante. Y, para no abundar en demostraciones tediosas, basta pensar en Williams y en Saer: los dos merecieron un lugar especial en la revista, los dos fueron canonizados y puestos a circular con éxito en el mundo de la academia y en buena parte del público lector, los dos fueron revisitados desde perspectivas autobiográficas, los dos se transformaron en verdaderas metonimias de "los dos ojos" de Punto de Vista: el historiador socialista y reformista; el escritor vanguardista, moderno, adorniano. Quizás esta tensión explique la fascinación de Sarlo por la narrativa de Sebald: su extrema originalidad radica en que es un escritor moderno, "testigo de las ruinas de la modernidad", 
que, sin embargo, conserva un resto de humanismo, una rara intensidad y un moralismo anacrónico; una suerte de extraña e imposible, quizás, síntesis de "los dos ojos".

En su artículo del número 76 de agosto del 2003, Sarlo reseña un libro de Susan Sontag sobre fotografía. Pocos números después, en el número 81 de abril del 2005, una columna editorial, firmada por Punto de Vista, da cuenta de "La partida de Susan Sontag", fallecida a fines de $2004 .{ }^{45}$ La columna, podemos conjeturar, la escribió Beatriz Sarlo, y al hablar de Sontag no hace más que hablar de sí misma, de la imagen buscada de sí misma:

Sensible como pocos a la fenomenología de la cultura moderna, no se sometió a los caprichos de sus capítulos finales ni, mucho menos, a la deriva posmoderna. [...] las intervenciones políticas de Sontag se sostuvieron en el prestigio adquirido como crítica de la cultura contemporánea. Es decir que Sontag transfirió de un campo a otro el prestigio ganado y supo hacerlo con un equilibrio austero que le permitió mantenerse tan firme en una como en otra dimensión de escritura.

Desde el comienzo, no fue una académica, a diferencia de Chomsky y de Said, sino, para decirlo con la expresión con que se designan en el mercado, una freelance writer.

También esto potencia la curiosidad de Sontag por los acontecimientos estéticos más diferentes: no está condenada a ellos profesionalmente y puede escribir sobre ellos con la soltura del ensayista. [...] fue una crítica que tuvo como objetos de elección la vanguardia y las nuevas sensibilidades, pero también se planteó ensayos de interpretación social, con base en la historia de las configuraciones simbólicas. (1)

Todo lo dicho sobre Sontag es aplicable, mutatis mutandi, a la trayectoria intelectual de Sarlo. Si nos ceñimos al objeto de nuestro trabajo — sus intervenciones en Punto de Vista -, de la primera a la última intervención persisten la capacidad de adelantar temas de discusión cuando nadie los discutía, la firmeza y coherencia en la defensa de ciertos principios, la reticencia a sumarse a las modas teóricas o a las agendas mediáticas, la pericia y la honestidad para pivotear en el incierto terreno de "los dos ojos": es una lectora formidable de la tradición y de las novedades del arte y la literatura; pero también una intelectual nunca indiferente a los debates y conflictos que atraviesan el mundo social y político.

\section{Referencias}

Altamirano, Carlos. "El intelectual en la represión y en la democracia”. Punto de Vista, n. ${ }^{\circ} 28$, noviembre de 1986, pp. $1-4$.

Altamirano, Carlos. "La fundación de la literatura argentina."Punto de Vista, n. ${ }^{\circ}$ 7, noviembre de 1979, pp. 10-12.

Altamirano, Carlos. "Raymond Williams: proposiciones para una teoría social de la cultura". Punto de Vista, n. ${ }^{\circ} 11$, marzo-junio de 1981, pp. 20-23.

Altamirano, Carlos y Beatriz Sarlo. Conceptos de sociología literaria. Centro Editor de América Latina, 1990.

Altamirano, Carlos y Beatriz Sarlo. Ensayos argentinos. De Sarmiento a la vanguardia. Ariel, 1997.

Altamirano, Carlos y Beatriz Sarlo. "Identidad, linaje y mérito en Sarmiento". Punto de Vista, n. ${ }^{\circ}$ 10, noviembre de 1980, pp. 14-19.

Altamirano, Carlos y Beatriz Sarlo. "Nosotros y ellos: David Viñas habla sobre Contorno". Punto de Vista, n. ${ }^{\circ}$ 13, noviembre de 1981, pp. 9-12.

Bobbio, Norberto. "Intelectuales y poder". La duda y la elección. Intelectuales y poder en la sociedad contemporánea. Paidós, 1998, pp. 57-81.

Bourdieu, Pierre. "El oficio de sociólogo". Punto de Vista, n. ${ }^{\circ}$ 15, agosto-octubre de 1982, pp 16-18.

Bourdieu, Pierre. "Por una internacional de los intelectuales". Intelectuales, politica y poder. Eudeba, 2000, pp. 187-196.

Catelli, Nora. "Los gestos de la posmodernidad". Punto de Vista, n. ${ }^{\circ} 22$, diciembre de 1984, p. 37.

Catelli, Nora. "Contorno en la cultura argentina”. Punto de Vista, n. ${ }^{\circ}$ 4, noviembre de 1978, pp. 7-10.

Dalmaroni, Miguel. “La moda y 'la trampa del sentido común'. Sobre la operación Raymond Williams en Punto de Vista”. Orbis Tertius, n. ${ }^{\circ}$ 5, 1997, pp. 13-21. 
Dalmaroni, Miguel. "De Los Libros a Punto de Vista, de Literal a Babel". La palabra justa. Literatura, crítica y memoria en la Argentina. 1960-2002. RIL Editores y Editorial Melusina, 2004, pp. 31-41.

Drucaroff, Elsa, directora del volumen. Historia crítica de la literatura argentina. La narración gana la partida. Tomo 11, Emecé Editores, 2000.

Eagleton, Terry. "La rebelión del lector”. Punto de Vista, n. ${ }^{2}$ 24, agosto-octubre de 1985, pp. 12-13.

Ferraris, Gustavo [seudónimo de Nicolás Rosa]. "Sarmiento: crítica y empirismo". Punto de Vista, n. 2 , mayo de 1978, pp. 6-11.

Gillier, Baptiste. "Punto de Vista (1978-1983): nacimiento de una nueva crítica”. Ensemble, vol. 4, n. ㅇ, 2011.

Gramuglio, María Teresa. "Continuidad entre la Ida y la Vuelta del Martín Fierro". Punto de Vista, n. ${ }^{\circ}$, noviembre de 1979, pp. 3-6.

Gramuglio, María Teresa. "El discreto encanto de Manuel Puig”. Punto de Vista, n. ${ }^{\circ}$ 8, marzo-junio de 1980, pp. 33-35.

Gramuglio, María Teresa. "Increíbles aventuras de una nieta de la cautiva”. Punto de Vista, n. ${ }^{\circ}$ 14, marzo-julio de 1982, pp. 27-28.

Gramuglio, María Teresa. "Juan José Saer: el arte de narrar”. Punto de Vista, n. 6, julio de 1979, pp. 3-8.

Gramuglio, María Teresa. "La filosofía en el relato". Punto de Vista, n. ${ }^{\circ}$ 20, mayo de 1984, pp. 35-36.

Gramuglio, María Teresa. "Las aventuras del orden”. Los Libros, n. ${ }^{\circ}$ 3, septiembre de 1969, p. 5.

Gramuglio, María Teresa. "Sur: constitución del grupo y proyecto cultural”. Punto de Vista, n. ${ }^{\circ}$ 17, abril-julio de 1983, pp. 7-9.

Gramuglio, María Teresa, et al. "Literatura, mercado y crítica. Un debate". Punto de Vista, n. ${ }^{\circ}$ 66, abril del 2000, pp. 1-9.

Jauss, Hans Robert. "Estética de la recepción y comunicación literaria”. Punto de Vista, n. ${ }^{\circ}$ 12, julio-octubre de 1981, pp. 34-40.

López Casanova, Martina. La palabra propia. Sobre la crítica literaria ensayistica y el intelectual como sujeto de enunciación (1970-2008). 2015. Universidad Nacional de General Sarmiento, tesis doctoral.

Merbilhaá, Margarita. "Juan José Saer en el sistema de lecturas de Punto de Vista". Tramas para leer la literatura argentina, n. ${ }^{\circ}$ 9, 1998, pp. 109-116.

Niccolini, Silvia [seudónimo de Beatriz Sarlo]. "La política del ochenta." Punto de Vista, n. ${ }^{\circ}$ 1, marzo de 1978, pp. $25-26$.

Olmos, Ana Cecilia. "Intelectuales, instituciones, tradiciones: Punto de Vista y Novos Estudos". Territorios intelectuales. Pensamiento y cultura en América Latina, coordinado por Javier Lasarte Valcárcel, Fondo Editorial La Nave Va, 2001, pp. 75-100.

Pagni, Andrea. "Relecturas de Borges y Sur por la izquierda intelectual argentina desde los años ochenta: el caso de Punto de vista". Actas del VII Congreso Nacional de Literatura Argentina. Facultad de Filosofía y Letras, Universidad Nacional de Tucumán, 1993, pp. 459-465.

Patiño, Roxana. "Intelectuales en transición. Las revistas culturales argentinas (1981-1987)”. Cuadernos de Recienvenido, n. ${ }^{\circ}$ 4, 1997, pp. 5-37.

Piglia, Ricardo. "Notas sobre Facundo". Punto de Vista, n. ${ }^{\circ}$ 8, marzo-junio de 1980, pp. 15-18.

Piglia, Ricardo. "Punto de Vista señala". Punto de Vista, n. ${ }^{\circ}$ 3, julio de 1978, pp. 18-19.

Sarlo, Beatriz. “'A Arcaicos o marginales? Situación de los intelectuales en el fin de siglo”. Punto de Vista, n. ${ }^{\circ}$ 47, diciembre de 1993, pp. 1-5.

Sarlo, Beatriz. "Arlt: ciudad real, ciudad imaginaria, ciudad reformada". Punto de Vista, n. ${ }^{\circ}$ 42, abril de 1992, pp. 15-20.

Sarlo, Beatriz. "Aventuras de un médico filósofo. Sobre Las nubes de Juan José Saer". Punto de Vista, n. ${ }^{\circ}$ 59, diciembre de 1997, pp. 35-38.

Sarlo, Beatriz. "Basuras culturales, simulacros políticos". Punto de Vista, n. ${ }^{\circ} 37$, julio de 1990, pp. 14-17

Sarlo, Beatriz. "Borges en Sur: un episodio del formalismo criollo". Punto de Vista, n. ${ }^{\circ}$ 16, noviembre de 1982, pp. 3-6.

Sarlo, Beatriz. "Borges pregunta sobre el orden". Punto de Vista, n. ${ }^{\circ} 43$, agosto de 1992, pp. 17-20.

Sarlo, Beatriz. Borges, un escritor en las orillas. Ariel, 1995. 
Sarlo, Beatriz. "Borges y la literatura argentina". Punto de Vista, n. ${ }^{\circ}$ 34, julio-septiembre de 1989, pp. 6-10.

Sarlo, Beatriz. “Crítica de la lectura, ¿un nuevo canon?”. Punto de Vista, n. ${ }^{\circ} 24$, agosto-octubre de 1985, pp. 7-11.

Sarlo, Beatriz. "El mejor. Juan José Saer (1937-2005)”. Punto de Vista, n. ${ }^{\circ} 82$, agosto de 2005, p. 1.

Sarlo, Beatriz. "El relativismo absoluto o cómo el mercado y la sociología reflexionan sobre estética". Punto de Vista, n. ${ }^{\circ}$ 48, abril de 1994, pp. 27-31.

Sarlo, Beatriz. "El saber del texto". Punto de Vista, n. ${ }^{\circ}$ 26, abril de 1986, pp. 6-7.

Sarlo, Beatriz. Escenas de la vida posmoderna. Ariel, 1994.

Sarlo, Beatriz. Escritos sobre literatura argentina. Editado por Sylva Saítta, Siglo XXI, 2007, pp. 384-386.

Sarlo, Beatriz. "Final". Punto de Vista, n. ${ }^{\circ}$ 90, abril de 2008, pp. 1-2.

Sarlo, Beatriz. "Intelectuales, ¿escisión o mímesis?". Punto de Vista, n. ${ }^{\circ}$ 25, pp. 1-6.

Sarlo, Beatriz. "Jaque a Paysandú, de María Esther de Miguel”. Punto de Vista, n. ${ }^{20}$, mayo de 1984, p. 44.

Sarlo, Beatriz. Jorge Luis Borges: A Writer on the Edge. Verso, 1993.

Sarlo, Beatriz. "La condición mortal". Punto de Vista, n. 4 46, agosto de 1993, pp. 28-31.

Sarlo, Beatriz. "La duda y el pentimento". Punto de Vista, n. ${ }^{\circ}$ 56, diciembre de 1996, pp. 31-35.

Sarlo, Beatriz. "La extensión”. Punto de Vista, n. ${ }^{\circ}$ 78, abril de 2004, pp. 12-18.

Sarlo, Beatriz. La imaginación técnica. Sueños modernos de la cultura argentina. Nueva Visión, 1992.

Sarlo, Beatriz. "La literatura de América Latina. Unidad y conflicto". Punto de Vista, n. ${ }^{\circ}$, marzo-junio de 1980, pp. 3-14.

Sarlo, Beatriz. "La moral de la crítica". Punto de Vista, n. ${ }^{15}$, agosto-octubre de 1982, pp. 21-22.

Sarlo, Beatriz. "La partida de Susan Sontag”. Punto de Vista, n. ${ }^{\circ}$ 81, abril de 2005, p. 1.

Sarlo, Beatriz. "La perspectiva americana en los primeros años de Sur". Punto de Vista, n. ${ }^{\circ}$ 17, abril-julio de 1983, pp. $10-12$.

Sarlo, Beatriz. “¿La voz universal que toma partido? Crítica y autonomía”. Punto de Vista, n. ${ }^{50}$, noviembre de 1994, pp. 5-9.

Sarlo, Beatriz. "Lectura sobre lectura". Punto de Vista, n. ${ }^{\circ}$ 89, diciembre de 2007, pp. 46-48.

Sarlo, Beatriz. "Literatura y política". Punto de Vista, n. ${ }^{\circ}$ 19, diciembre de 1983, pp. 8-11.

Sarlo, Beatriz. "Los dos ojos de Contorno". Punto de Vista, n. ${ }^{\circ}$ 13, noviembre de 1981, pp. 3-8.

Sarlo, Beatriz. "Narrar la percepción”. Punto de Vista, n. ${ }^{\circ}$ 10, noviembre de 1980, pp. 34-37.

Sarlo, Beatriz. "Olvidar a Benjamin". Punto de Vista, n. ${ }^{\circ}$ 53, noviembre de 1995, pp. 16-19.

Sarlo, Beatriz. "Política, ideología y figuración literaria". Ficción y política. La narrativa argentina durante el proceso militar, por Balderston et al., Alianza Estudio, 1987, pp. 30-59.

Sarlo, Beatriz. "Prohibido escupir sangre, de Guillermo Saccomano". Punto de Vista, n. ${ }^{\circ} 20$, mayo de 1984, p. 45.

Sarlo, Beatriz. "Raymond Williams y Richard Hoggart: sobre cultura y sociedad". Punto de Vista, n. ${ }^{\circ}$ 6, julio de 1979, pp. 9-18.

Sarlo, Beatriz. "Raymond Williams: una relectura". Punto de Vista, n. ${ }^{4}$ 45, abril de 1993, pp. 12-15.

Sarlo, Beatriz. "Razones de la aflicción y el desorden en Martín Fierro". Punto de Vista, n. ${ }^{\circ}$ 7, noviembre de 1979, pp. 7-9

Sarlo, Beatriz. "Sobre la vanguardia, Borges y el criollismo". Punto de Vista, n. ${ }^{\circ}$ 11, marzo-junio de 1981, pp. 3-8.

Sarlo, Beatriz. "Sujetos y tecnologías. La novela después de la historia”. Punto de Vista, n. ${ }^{\circ}$ 86, diciembre de 2006, pp. 1-6.

Sarlo, Beatriz. "Un tratado moral. Sontag, de nuevo sobre la fotografía". Punto de Vista, n. ${ }^{\circ}$ 76, agosto de 2003, pp. 6-10.

Sarlo, Beatriz. Una modernidad periférica. Buenos Aires, 1920 y 1930. Nueva Visión, 1988.

Sosnowski, Saúl, editor. La cultura de un siglo. América latina en sus revistas. Alianza, 1999.

Victorini, Washington [seudónimo de Carlos Altamirano y Beatriz Sarlo]. "Martínez Estrada: de la crítica a Martín Fierro al ensayo sobre el ser nacional”. Punto de Vista, n. ${ }^{\circ} 4$, noviembre de 1978, pp. 3-6.

Viñas, David. “Los dos ojos del romanticismo". Contorno, n. ${ }^{\circ}$ 5/6, septiembre de 1955, pp. 2-5. 
Warley, Jorge. “Un acuerdo de orden ético”. Punto de Vista, n. ${ }^{\circ}$ 17, abril-julio de 1983, pp. 12-14.

\section{Anexo}

Beatriz Sarlo en Punto de Vista

\section{Listado de artículos, reseñas e intervenciones en debates}

Año I, n. ${ }^{\circ}$ 1, marzo de 1978

Silvia Niccolini [seudónimo de Beatriz Sarlo]. "La política del ochenta”. Reseña de El orden conservador, de Natalio Botana (pp. 25-26)

Año I, n. ${ }^{\circ}$ 2, mayo de 1978

Silvia Niccolini [seudónimo de Beatriz Sarlo]. “¿Cómo leer literatura? Algunas consideraciones sobre el formalismo norteamericano" (pp. 3-5)

Año I, n. ${ }^{\circ}$ 3, julio de 1978

Silvia Niccolini [seudónimo de Beatriz Sarlo]. “Fassbinder: por un cine de ideas” (pp. 28-31)

Año I, n. ${ }^{\circ}$, noviembre de 1978

Washington Victorini [seudónimo de Carlos Altamirano y Beatriz Sarlo]. "Martínez Estrada: de la crítica a Martín Fierro al ensayo sobre el ser nacional" (pp. 3-6)

Año II, n. ${ }^{\circ}$ 6, julio de 1979

“Raymond Williams y Richard Hoggart: sobre cultura y sociedad”. Entrevista (pp. 9-18)

[T4]Año II, n. ${ }^{\circ}$ 7, noviembre de 1979

"Razones de la aflicción y el desorden en Martín Fierro" (pp. 7-9) [integra un dossier, a cien años de la Vuelta, junto a textos de Carlos Altamirano y María Teresa Gramuglio]

Año III, n. ${ }^{\circ}$ 8, marzo-junio de 1980

"La literatura de América Latina. Unidad y conflicto". Entrevistas a António Cândido, Ángel Rama y Antonio Cornejo Polar (pp. 3-14) 
Año III, n. ${ }^{\circ} 10$, noviembre de 1980

En colaboración con Carlos Altamirano. "Identidad, linaje y mérito en Sarmiento" (pp. 14-19)

"Narrar la percepción”. Reseña de Nadie nada nunca, de Juan José Saer (pp. 34-37)

Año IV,n.o 11, marzo-junio de 1981

"Sobre la vanguardia, Borges y el criollismo" (pp. 3-8)

Año IV, n. ${ }^{\circ} 13$, noviembre de 1981

"Los dos ojos de Contorno" (pp. 3-8)

En colaboración con Carlos Altamirano. "Nosotros y ellos. David Viñas habla sobre Contorno”. Entrevista (pp. 9-12)

Año $V, n .^{\circ} 15$, agosto-octubre de 1982

“La moral de la crítica”. Reseña sobre Literatura argentina y realidad politica, de David Viñas (pp. 21-22)

Año $V, n .^{\circ} 16$, noviembre de 1982

"Borges en Sur: un episodio del formalismo criollo" (pp. 3-6)

Año VI, n. ${ }^{\circ} 17$, abril-julio de 1983

"La perspectiva americana en los primeros años de Sur" (pp. 10-12) [integra un dossier sobre Sur, junto a textos de Gramuglio y Jorge Warley]

Año VI, n. ${ }^{\circ} 18$, agosto de 1983

"La perseverancia de un debate" (pp. 3-5) [integra un dossier sobre "Cultura nacional y cultura popular", del que participan Altamirano, el programa PEHESA, Jorge E. Dotti y Carlos Real de Azúa]

Año VI, n. ${ }^{\circ}$ 19, diciembre de 1983

"Literatura y política” (pp. 8-11)

Año VII, n. ${ }^{\circ} 20$, mayo de 1984

"La izquierda ante la cultura: del dogmatismo al populismo" (pp. 22-25) 
Año VII, n. ${ }^{\circ} 21$, agosto de 1984

"Una alucinación dispersa en agonía" (pp. 1-4)

"La novela como viaje". Reseña de Fuego a discreción, de Antonio Dal Masetto (pp. 40-41)

Año VII, n. ${ }^{\circ} 22$, diciembre de 1984

En colaboración con Hilda Sabato. "Historia y ficción" (pp. 8-12)

"Una novela de la distancia”. Reseña de El pasajero, de Rodolfo Rabanal (pp. 34-35)

Año VIII, n. ${ }^{\circ} 24$, agosto-octubre de 1985

“Crítica de la lectura, ¿un nuevo canon?” (pp. 7-11)

Año VIII, n. ${ }^{\circ} 25$, diciembre de 1985

“Intelectuales, ¿escisión o mímesis?” (pp. 1-6)

Año IX, n. ${ }^{\circ}$ 26, abril de 1986

"El saber del texto" (pp. 6-7) [integra el dossier "Estética y política”]

Año IX, n. ${ }^{\circ} 27$, agosto de 1986

“Una mirada política. Defensa del partidismo en el arte" (pp. 1-4)

"El riesgo de la literatura”. Reseña de Apuestas, de Andrés Rivera (pp. 23-24)

Año IX, n. ${ }^{\circ} 28$, noviembre de 1986

"Clío revisitada” (pp. 23-26)

Año X, n. ${ }^{\circ}$ 30, julio-octubre de 1987

"No retroceder" (p. 4)

"Los militares y la historia: contra los perros del olvido" (pp. 5-8)

Año XI, n. ${ }^{\circ}$ 32, abril-junio de 1988

"Políticas culturales: democracia e innovación" (pp. 8-13) 
Año XI, n. ${ }^{\circ} 33$, septiembre-diciembre de 1988

"Una legislación para los mass-media" (pp. 15-19)

Año XII, n. ${ }^{\circ}$ 34, julio-septiembre de 1989

"Borges y la literatura argentina” (pp. 6-10)

Año XII, n. ${ }^{\circ}$ 35, septiembre-noviembre de 1989

"Lo popular en la historia de la cultura" (pp. 19-24)

Año XII, n. ${ }^{\circ}$ 36, diciembre de 1989

“La historia contra el olvido" (pp. 11-13)

Año XIII, n. ${ }^{\circ} 37$, julio de 1990

“Basuras culturales, simulacros políticos” (pp. 14-17)

Año XIII, n. ${ }^{\circ}$ 38, octubre de 1990

“La imaginación del futuro" (pp. 15-17)

Año XIII, n. ${ }^{\circ}$ 39, diciembre de 1990

“Menem" (pp. 1-4)

Año XIV, n. ${ }^{\circ} 40$, julio-septiembre de 1991

“La guerra del Golfo: representaciones pospolíticas y análisis cultural” (pp. 28-31)

Año XIV, n. ${ }^{\circ} 41$, diciembre de 1991

“El audiovisual político” (pp. 18-20)

Año XV, n. ${ }^{\circ} 42$, abril de 1992

"Arlt: ciudad real, ciudad imaginaria, ciudad reformada" (pp. 15-20) 
Año XV, n. ${ }^{\circ} 43$, agosto de 1992

“Borges pregunta sobre el orden” (pp. 17-20)

Año $X V, n .^{\circ} 44$, noviembre de 1992

"La teoría como chatarra. Tesis de Oscar Landi sobre la televisión" (pp. 12-18)

Año XVI, n. ${ }^{\circ} 45$, abril de 1993

"Raymond Williams: una relectura” (pp. 12-15)

Año XVI, n. ${ }^{\circ} 46$, agosto de 1993

“La condición mortal” (pp. 28-31)

Año XVI, n. ${ }^{\circ} 47$, diciembre de 1993

“AArcaicos o marginales? Situación de los intelectuales en el fin de siglo” (pp. 1-5)

Año XVII, n. ${ }^{\circ} 48$, abril de 1994

"El relativismo absoluto o cómo el mercado y la sociología reflexionan sobre estética” (pp. 27-31)

Año XVII, n. ${ }^{\circ} 49$, agosto de 1994

"No olvidar la guerra de Malvinas. Sobre cine, literatura e historia" (pp. 11-15)

"Boris Spivacow: la muerte del constructor" (pp. 47-48)

Año XVII, n. ${ }^{\circ}$ 50, noviembre de 1994

“¿La voz universal que toma partido? Crítica y autonomía” (pp. 5-9)

Año XVIII, n. ${ }^{\circ}$ 51, abril de 1995

"Experiencia y lenguaje II" (pp. 5-6) [integra un dossier: "Experiencia y lenguaje I", con testimonios de Juan Martini, Alan Pauls y Héctor Tizón, y “Experiencia y lenguaje III”, dos ensayos de Juan José Saer]

Año XVIII, n. ${ }^{\circ}$ 52, agosto de 1995

"La democracia mediática y sus límites" (pp. 11-16) 
Año XVIII, n. ${ }^{\circ}$ 53, noviembre de 1995

“Olvidar a Benjamin” (pp. 16-19)

Año XIX, n. ${ }^{\circ}$ 54, abril de 1996

“Coincidencias: Villa de Luis Gusmán” (pp. 4-7)

Año XIX, n. ${ }^{\circ} 55$, agosto de 1996

"Retomar el debate" (pp. 38-42)

Año XIX, n. ${ }^{\circ}$ 56, diciembre de 1996

"La duda y el pentimento" (pp. 31-35)

Año XX, n. ${ }^{\circ} 57$, abril de 1997

"Anomalías" (pp. 21-23)

Año XX, n. ${ }^{\circ} 58$, agosto de 1997

“Cuando la política era joven” (pp. 15-19)

Año XX, n. ${ }^{\circ} 59$, diciembre de 1997

“Aventuras de un médico filósofo. Sobre Las nubes de Juan José Saer” (pp. 35-38)

Año XXI, n. ${ }^{\circ}$ 60, abril de 1998

"Imágenes" (pp. 42-46) [el artículo se inscribe en el subtítulo "Cine” y Beatriz Sarlo participa, además, de la "discusión" de las páginas 46-49; por otra parte, también participa de la "discusión" sobre "Música", en las páginas 33-35]

Año XXI, n. ${ }^{\circ}$ 61, agosto de 1998

"Debate sobre política e ideas" (pp. 18-30) [participa junto a Altamirano, Jorge Dotti, Adrián Gorelik, Gramuglio, Hilda Sabato, Oscar Terán y Hugo Vezzetti]

Año XXI, n. ${ }^{\circ}$ 62, diciembre de 1998

“Lugar de origen” (pp. 33-36) 
Año XXII, n. ${ }^{\circ}$ 63, abril de 1999

"Educación: el estado de las cosas" (pp. 17-21)

Año XXII, n. ${ }^{\circ}$ 64, agosto de 1999

"Una cultura, varias ciudades, dos novelas" (pp. 12-16)

Año XXII, n. ${ }^{\circ}$ 65, diciembre de 1999

"Debates sobre la transición” (pp. 1-12) [participa junto a Altamirano, Jorge Dotti, Adrián Gorelik, Gramuglio, Hilda Sabato, Oscar Terán y Hugo Vezzetti]

Año XXIII, n. ${ }^{\circ}$ 66, abril de 2000

"Literatura, mercado y crítica. Un debate" (pp. 1-9) [participa junto a Gramuglio, Martín Prieto y Matilde Sánchez]

Año XXIV, n. ${ }^{\circ}$ 69, abril de 2001

“W. G. Sebald: un maestro de la paráfrasis" (pp. 1-4)

Año XXIV, n. ${ }^{\circ} 70$, agosto de 2001

"Ya nada será igual" (pp. 2-11)

Año XXIV, n. ${ }^{\circ} 71$, diciembre de 2001

"Fogwill: la experiencia sensible” (pp. 27-31)

Año XXV, n. ${ }^{\circ} 72$, julio-octubre de 2002

“De nuevo, y quizás por última vez, sobre Sebald” (pp. 16-19)

Año XXV, n. ${ }^{\circ} 73$, agosto de 2002

“Épica de la multitud o de la consolación por la filosofía” (pp. 4-9)

Año XXV, n. ${ }^{\circ} 74$, diciembre de 2002

“El dilema” (pp. 1-5) [integra el dossier “¿Hay futuro para la Argentina?”] 
Año XXVI, n. ${ }^{\circ} 75$, abril de 2003

"Lecturas de verano" (pp. 12-16)

Año XXVI, n. ${ }^{\circ} 76$, agosto de 2003

"Un tratado moral. Sontag, de nuevo sobre la fotografía" (pp. 6-10)

Año XXVI, n. ${ }^{\circ} 77$, diciembre de 2003

"Una escenografía para 'El holandés errante”" (pp. 11 y 13) [integra el dossier "Un estado del arte: el fenómeno Kuitca”]

Año XXVII, n. ${ }^{\circ} 78$, abril de 2004

"La extensión" (pp. 12-18) [integra el dossier "La modernidad en cuestión"]

Año XXVII, n. ${ }^{\circ} 79$, agosto de 2004

"La diatriba” (pp. 35-36) [integra el dossier "Belleza, espacio, utopía y política. Films del VI BAFICI"]

Año XXVII, n. ${ }^{\circ} 80$, diciembre de 2004

"Doble óptica. Un intento (más) de observar el peronismo" (pp. 1-5)

Año XXVIII, n. ${ }^{\circ} 81$, abril de 2005

"Cine documental: la objetividad en cuestión" (pp. 14-23) [debate editado por Beatriz Sarlo, en el que participan Raúl Beceyro, Rafael Filippelli, Hernán Hevia, Martín Kohan, Jorge Myers, David Oubiña, Santiago Palavecino, Beatriz Sarlo, Silvia Schwarzböck y Graciela Silvestri]

Año XXVIII, n. ${ }^{\circ} 82$, agosto de 2005

“El mejor. Juan José Saer (1937-2005)” (p. 1)

"Cine documental: la primera persona" (pp. 27-36) [debate editado por Beatriz Sarlo, en el que participan Raúl Beceyro, Rafael Filippelli, Hernán Hevia, Martín Kohan, Jorge Myers, David Oubiña, Santiago Palavecino, Beatriz Sarlo, Silvia Schwarzböck y Graciela Silvestri]

Año XXVIII, n. ${ }^{\circ} 83$, diciembre de 2005

“:Pornografía ofashion?” (pp. 13-17) 
Año XXIX, n. ${ }^{\circ} 84$, abril de 2006

“Conflictos y representaciones culturales" (pp. 2-7) [primer artículo de la serie "El juicio del siglo"]

Año XXIX, n. ${ }^{\circ} 85$, agosto de 2006

"Los modos de hacer" (pp. 23-28) [conversación con Eduardo Stupía, de Graciela Silvestri y Beatriz Sarlo]

"La estética de las buenas causas" (pp. 29-34)

Año XXIX, n. ${ }^{\circ} 86$, diciembre de 2006

“Sujetos y tecnologías. La novela después de la historia” (pp. 1-6)

Año XXX, n. ${ }^{\circ} 87$, abril de 2007

“¿El último avatar?” (pp. 1-5)

Año XXX, n. ${ }^{\circ} 88$, agosto de 2007

“Un cine conceptual” (pp. 37-38) [integra el dossier "El cine que no vemos"]

Año XXX, n. ${ }^{\circ} 89$, diciembre de 2007

"Lectura sobre lectura” (pp. 46-48)

Año XXXI, n. ${ }^{\circ}$ 90, abril de 2008

"Final" (pp. 1-2)

"Melancolía e insistencia de la novela" (pp. 13-17)

\section{Notas}

\section{* Artículo de investigación}

1 El presente trabajo estaba originalmente ordenado en seis apartados: 1) literatura argentina: el pasado; 2) literatura argentina: el presente; 3) intelectuales; 4) teoría literaria, teoría cultural; 5) política e ideas; 6) industria cultural, medios. Creía que a partir de esas seis coordenadas podía brindar un panorama más o menos abarcadorde la labor crítica de Sarlo en Punto de Vista. Lamentablemente, las limitaciones de espacio me obligaron a reducir el artículo solo a los cuatro primeros apartados.

2 Niccolini, Silvia [seudónimo de Beatriz Sarlo]. “La política del ochenta”. Punto de Vista, n. ${ }^{\circ}$ 1, marzo de 1978, pp. 25-26.

3 El texto es inédito; fue expuesto en las "Jornadas sobre revistas científicas, independientes y de divulgación", en la Facultad de Humanidades de la Universidad Nacional de La Plata, en septiembre de 1996. El texto de aquella conferencia se recuperó, con modificaciones, en el artículo de Beatriz Sarlo, "Punto de Vista: una revista en dictadura y en democracia" (en Sosnowski 525-533).

4 Sobre los modos de ciframiento en Punto de Vista, véase López Casanova. 
5 Ferraris, Gustavo [seudónimo de Nicolás Rosa]. "Sarmiento: crítica y empirismo”. Punto de Vista, n. ${ }^{\circ}$, mayo de 1978, pp. 6-11; Piglia, Ricardo. "Notas sobre Facundo". Punto de Vista, n. ${ }^{\circ}$ 8, marzo-junio de 1980, pp. 15-18; Altamirano, Carlos y Beatriz Sarlo. "Identidad, linaje y mérito en Sarmiento".Punto de Vista, n. ${ }^{\circ}$ 10, noviembre de 1980, pp. 14-19.

6 Victorini, Washington [seudónimo de Carlos Altamirano y Beatriz Sarlo]. "Martínez Estrada: de la crítica a Martín Fierro al ensayo sobre el ser nacional". Punto de Vista, n. ${ }^{4}$, noviembre de 1978, pp. 3-6.

7 Gramuglio, María Teresa. “Continuidad entre la Ida y la Vuelta del Martín Fierro”. Punto de Vista, n. ${ }^{\circ}$ 7, noviembre de 1979, pp. 3-6; Sarlo, Beatriz. "Razones de la aflicción y el desorden en Martín Fierro". Punto de Vista, n. ${ }^{\circ}$, noviembre de 1979, pp. 7-9; Altamirano, Carlos. "La fundación de la literatura argentina”, Punto de Vista, n. ${ }^{\circ}$, noviembre de 1979, pp. 10-12.

8 "Sobre la vanguardia, Borges y el criollismo". Punto de Vista, n. ${ }^{\circ}$ 11, marzo-junio de 1981, pp. 3-8; "Borges en Sur: un episodio del formalismo criollo". Punto de Vista, n. ${ }^{\circ}$ 16, noviembre de 1982, pp. 3-6; "Borges y la literatura argentina”. Punto de Vista, n. 34 , julio-septiembre de 1989, pp. 6-10; “Borges pregunta sobre el orden”. Punto de Vista, n. ${ }^{43}$, agosto de 1992, pp. 17-20.

9 Cuatro años después, estas hipótesis se consolidan en el libro Borges, un escritor en las orillas , publicado en inglés en 1993 (Londres: Verso) y en español en 1995 (Buenos Aires: Ariel).

10 Gramuglio, María Teresa. “Sur: constitución del grupo y proyecto cultural”. Punto de Vista, n. ${ }^{\circ}$ 17, abril-julio de 1983, pp. 7-9; Sarlo, Beatriz. "La perspectiva americana en los primeros años de Sur". Punto de Vista, n. 17, abril-julio de 1983, pp. 10-12; Warley, Jorge. "Un acuerdo de orden ético". Punto de Vista, n. ${ }^{\circ}$ 17, abril-julio de 1983, pp. 12-14.

11 “Contorno en la cultura argentina”. Punto de Vista, n. ${ }^{4}$, noviembre de 1978, pp. 7-10.

12 Respecto de cómo Punto de Vista fue construyendo sus linajes, véase Olmos (83 y ss.).

13 Sarlo, Beatriz. "Los dos ojos de Contorno". Punto de Vista, n. ${ }^{\circ}$ 13, noviembre de 1981, pp. 3-8. El artículo se publicó seguido de un reportaje hecho a David Viñas, a cargo de Sarlo y Altamirano: "Nosotros y ellos: David Viñas habla sobre Contorno". Punto de Vista, n. ${ }^{\circ}$ 13, noviembre de 1981, pp. 9-12. El texto original de Viñas, "Los dos ojos del romanticismo", se publicó en Contorno, n. ${ }^{\circ}$ /6, septiembre de 1955 , pp. $2-5$.

14 Sarlo, Beatriz. "La moral de la crítica" (Reseña de Literatura argentina y realidad politica, de David Viñas). Punto de Vista, n. ${ }^{\circ} 15$, agosto-octubre de 1982, pp. 21-22.

15 Sarlo, Beatriz. "Arlt: ciudad real, ciudad imaginaria, ciudad reformada”. Punto de Vista, n. 0 42, abril de 1992, pp. 15-20. En verdad, se trata de una interpretación de la imaginación urbana de Arlt, en comparación con la de dos grandes arquitectos: Le Corbusier y Wladimiro Acosta.

16 Solo un par de referencias: antes, en Una modernidad periférica (1988); en el mismo año (1992), en La imaginación técnica. Además, en la recopilación Escritos sobre literatura argentina, que compiló Saítta, se incluyen cinco artículos sobre Arlt, ninguno de ellos publicado originalmente en Punto de Vista.

17 Sarlo, Beatriz. "La duda y el pentimento". Punto de Vista, n. ${ }^{\circ}$ 56, diciembre de 1996, pp. 31-35.

18 Respectivamente, Sarlo, Beatriz. “Basuras culturales, simulacros políticos”. Punto de Vista, n. ${ }^{\circ}$ 37, julio de 1990, pp. 14-17; y "La extensión”.Punto de Vista, n. ${ }^{\circ}$ 78, abril de 2004, pp. 12-18.

19 Indico entre paréntesis el número de las revistas en las que aparecieron las reseñas.

20 Para consultar la reseña de Saccomano, véase "Prohibido escupir sangre, de Guillermo Saccomano". Punto de Vista, n. 20 , mayo de 1984, p. 45; para consultar la reseña de De Miguel, véase “Jaque a Paysandú, María Esther de Miguel”. Punto de Vista, n. ${ }^{\circ}$ 20, mayo de 1984, p. 44; para consultar la reseña de Saer, véase "Aventuras de un médico filósofo. Sobre Las nubes de Juan José Saer". Punto de Vista, n. ${ }^{\circ}$ 59, diciembre de 1997, pp. 35-38.

21 Sarlo, Beatriz. "Narrar la percepción”. Punto de Vista, n. ${ }^{\circ}$ 10, noviembre de 1980, pp. 34-37; "La condición mortal". Punto de Vista, n. ${ }^{\circ}$ 46, agosto de 1993, pp. 28-31; “Aventuras de un médico filósofo. Sobre Las nubes de Juan José Saer”. Punto de Vista, n. ${ }^{\circ}$ 59, diciembre de 1997, pp. 35-38; “El mejor. Juan José Saer (1937-2005)”. Punto de Vista, n. ${ }^{\circ}$ 82, agosto de 2005, p. 1; “Lectura sobre lectura”. Punto de Vista, n. ${ }^{8}$ 9, diciembre de 2007, pp. 46-48.

22 Aunque en este trabajo me limite exclusivamente a los artículos de Sarlo, cito solo un par de trabajos María Teresa Gramuglio: "Juan José Saer: el arte de narrar". Punto de Vista, n. ${ }^{6}$, julio de 1979, pp. 3-8; "La filosofía en el relato". Punto de Vista, n. 20 , mayo de 1984, pp. 35-36. Tempranamente, en 1969, Gramuglio ya había focalizado su interés en la obra de Saer: véase "Las aventuras 
del orden". Los Libros, n. ${ }^{\circ}$ 3, septiembre de 1969, p. 5. Margarita Merbilhaá ha señalado con agudeza las diferencias que advierte en los artículos de Sarlo respecto de los de Gramuglio.

23 Véase “El mejor. Juan José Saer (1937-2005)”.

24 Véase "Lectura sobre lectura".

25 A manera de ejemplo, en el tomo 11 de la Historia crítica de la literatura argentina, que dirigió Elsa Drucaroff, estos son los únicos tres autores cuya obra merece una consideración exclusiva; en el apartado "Figuras", pueden leerse los trabajos de José Amicola (Puig), de Miguel Dalmaroni y Margarita Merbilhá́ (Saer) y de Jorge Fornet (Piglia).

26 Solo están presentes en los dos panoramas que comentaremos unas líneas más abajo y en el debate sobre "Literatura, mercado y crítica. Un debate” (número 66, abril de 2000), en el que Sarlo relativiza el valor de las obras de Puig y de Aira.

27 Hablo de una decisión de Sarlo, no de la revista, ya que María Teresa Gramuglio reseña Pubis angelical (número 8, 33-35), de Puig, y se publican reseñas de Gramuglio sobre Ema, la cautiva (número 14, 27-28) y de Nora Catelli sobre Canto Castrato (número 22, 37), ambas de César Aira.

28 Sarlo, Beatriz. "Literatura y política". Punto de Vista, n. ${ }^{\circ}$ 19, diciembre de 1983, pp. 8-11; "Sujetos y tecnologías. La novela después de la historia". Punto de Vista , n. ${ }^{8} 86$, diciembre de 2006, pp. 1-6.

29 Andrea Pagni reinterpreta la hipótesis de Sarlo a partir de una perspectiva adorniana, como la tensión entre una estética afirmativa y una estética negativa. Véase "Relecturas de Borges y Sur por la izquierda intelectual argentina desde los años ochenta: el caso de Punto de vista".

30 Como nota final a este apartado, habría que agregar unas líneas sobre la literatura de Sergio Chejfec, quien colaboró como articulista en Punto de Vista y allí le publicaron textos narrativos. En "Anomalías" (número 57, de abril de 1997), Sarlo prologa uno de esos textos, y en sus Escritos sobre literatura argentina se incluyen dos reseñas, sobre El aire y Boca de lobo. Sarlo dice conocer la narrativa de Chejfec desde sus inicios y haberla acompañado desde entonces como su crítica. Si bien no se manifiesta en sus reseñas la admiración que le motivaba la narrativa de Saer, sí se podría afirmar que Chejfec ha venido ocupando, tibiamente, el lugar de Saer en la crítica literaria de Sarlo, tanto en la reivindicación de su apuesta estética como en la voluntad de reconocimiento y canonización de una obra no tan difundida.

31 Sarlo, Beatriz. "Intelectuales, ¿escisión o mímesis?”. Punto de Vista, n. ${ }^{\circ}$ 25, diciembre de 1985, pp. 1-6; “'Arcaicos o marginales? Situación de los intelectuales en el fin de siglo". Punto de Vista, n. ${ }^{\circ} 47$, diciembre de 1993, pp. 1-5; "¿La voz universal que toma partido? Crítica y autonomía". Punto de Vista, n. ${ }^{\circ}$ 50, noviembre de 1994, pp. 5-9.

32 Aquí utilizo representación en el sentido de delegación política (Vertreten), no en el sentido de representación artística o literaria (Darstellen).

33 Niccolini, Silvia [seudónimo de Beatriz Sarlo]. “¿Cómo leer literatura? Algunas consideraciones sobre el formalismo norteamericano". Punto de Vista, n. ${ }^{\circ}$ 2, mayo de 1978, pp. 3-5.

34 Sarlo, Beatriz. "Raymond Williams y Richard Hoggart: sobre cultura y sociedad". Punto de Vista, n. ${ }^{\circ}$ 6, julio de 1979, pp. 9-18; Altamirano, Carlos. "Raymond Williams: proposiciones para una teoría social de la cultura". Punto de Vista, n. ${ }^{\circ} 11$, marzojunio de 1981, pp. 20-23; Sarlo, Beatriz. "Raymond Williams: una relectura". Punto de Vista, n. ${ }^{\circ} 45$, abril de 1993, pp. 12-15.

35 Miguel Dalmaroni se refiere a lo que llamó la "operación Raymond Williams" en Punto de Vista. Dicha operación permitió al menos tres cosas: 1) "emprender una profilaxis antiparisina, es decir antiformalista, mediante un retorno al sujeto, a la historia y a la experiencia"; 2) "alentar una esperanza, la de seguir pensando conexiones entre cultura y política, y por tanto la de mantener lazos entre crítica de la cultura e intervención en el debate público o político"; 3) “ejercitar una estética vanguardista de la teoría"; la obra de Williams era un "foco teórico novedoso" que les permitía "abandonar un socialismo indefectiblemente dependiente del concepto de 'revolución' sin abandonar del todo el socialismo" ("La moda" 1-2).

36 Bourdieu, Pierre. "El oficio de sociólogo". Punto de Vista, n. 15, agosto-octubre de 1982, pp. 16-18.

37 Sarlo, Beatriz. "El relativismo absoluto o cómo el mercado y la sociología reflexionan sobre estética". Punto de Vista, n. ${ }^{\circ} 48$, abril de 1994, pp. 27-31.

38 Sarlo, Beatriz. "El saber del texto". Punto de Vista, n. ${ }^{\circ}$ 26, abril de 1986, pp. 6-7. El artículo forma parte de un dossier sobre "Estética y política". 
39 Sarlo, Beatriz. "Política, ideología y figuración literaria”. Ficción y política. La narrativa argentina durante el proceso militar, por Balderston et al., Alianza Estudio, 1987, pp. 30-59.

40 Sarlo, Beatriz. "Olvidar a Benjamin". Punto de Vista, n. ${ }^{\circ}$ 53, noviembre de 1995, pp. 16-19.

41 Jauss, Hans Robert. "Estética de la recepción y comunicación literaria”. Punto de Vista, n. ${ }^{\circ}$ 12, julio-octubre de 1981, pp. $34-40$.

42 Eagleton, Terry. "La rebelión del lector". Punto de Vista, n. 24, agosto-octubre de 1985, pp. 12-13; Sarlo, Beatriz. "Crítica de la lectura, ¿un nuevo canon?”. Punto de Vista, n. ${ }^{\circ} 24$, agosto-octubre de 1985, pp. 7-11.

43 Para una detallada reseña del proceso de modernización teórica en Punto de Vista, véase Gillier, apartado 2.

44 No he mencionado, en el estudio de las teorías literarias y culturales, a referentes latinoamericanos, porque no han ocupado un lugar relevante en la reflexiones de Sarlo. Sin embargo, no quiero omitir la entrevista que la autora realizó en Campinas, Brasil, a comienzos de 1980, a António Cândido, Ángel Rama y Antonio Cornejo Polar. En la entrevista se puede advertir —en especial, en la de Cândido- que se prolongan las preocupaciones teóricas para resolver las múltiples y complejas relaciones entre política, cultura y literatura, presentes en la entrevista a Raymond Williams, publicada solo unos pocos meses antes. Véase Sarlo, Beatriz. "La literatura de América Latina. Unidad y conflicto". Punto de Vista, n. ${ }^{\circ}$ 8, marzo-junio de 1980, pp. 3-14.

45 Sarlo, Beatriz. "Un tratado moral. Sontag, de nuevo sobre la fotografía”. Punto de Vista, n. ${ }^{\circ}$ 76, agosto de 2003, pp. 6-10; "La partida de Susan Sontag”. Punto de Vista, n. ${ }^{\circ} 81$, abril de 2005, p. 1.

\section{Licencia Creative Commons CC BY 4.0}

Cómo citar este artículo: De Diego, José Luis. "Beatriz Sarlo en Punto de Vista". Cuadernos de Literatura, vol. 24, 2020. https://doi.org/10.11144/Javeriana.cl24.bspv 